\title{
Validitas Media Pembelajaran Menggunakan Aplikasi Focusky Dilengkapi Buku Panduan pada Materi Protista untuk Peserta Didik Kelas X SMA
}

\author{
Agatha Pratiwi $^{1 *}$, Armen $^{1}$, Sa'diatul Fuadiyah $^{1}$, Relsas Yogica $^{1}$ \\ ${ }^{1)}$ Program Studi Pendidikan Biologi, FMIPA, Universitas Negeri Padang, Padang, Indonesia \\ Pengiriman: 15 Nopember; Diterima: 27 Nopem ber; Publikasi: 28 Nopember 2019
}

\begin{abstract}
The availability and use of instructional media that fits the needs of students becomes a problem in learning biology at SMAN 2 BatangAnai, especially in protist material. This is due to the limited skills of teachers in obtaining and developing learning media according to the needs of students. One alternative problem is to develop learning media using the Focusky application equipped with a manufacturing manual. Focusky application will produce learning media that can stimulate students' learning styles with the advantages of drag and drop methods. The purpose of this study was to produce learning media using the Focusky application equipped with a guidebook on protist material for valid class $\mathrm{X}$ students. This research is development research (Research and Development) with the Instructional Development Institute (IDI) model which consists of the stages of defining, developing, and evaluating. The research subjects were two biology lecturers at FMIPA UNP and one biology teacher at SMAN 2 BatangAnai. The object of research is learning media using the Focusky application on protist material equipped with a guidebook for class X SMA students. The research data is primary data in the form of data validity which is obtained directly through the provision of validation questionnaires to the research subjects. Based on the results of the study produced learning media using the Focusky application on protist material equipped with a guidebook for students of class $\mathrm{X}$ that are valid with an average validity value of $88.82 \%$.
\end{abstract}

Keywords: Validity, Focusky, Guided Book.

\begin{abstract}
ABSTRAK: Ketersediaan dan penggunaan media pembelajaran yang sesuai dengan kebutuhan siswa menjadi masalah dalam pembelajaran biologi di SMAN 2 BatangAnai, terutama dalam materi protista. Hal ini disebabkan oleh keterbatasan keterampilan guru dalam memperoleh dan mengembangkan media pembelajaran sesuai dengan kebutuhan siswa. Salah satu masalah alternatif adalah mengembangkan media pembelajaran menggunakan aplikasi Focusky yang dilengkapi dengan manual manufaktur. Aplikasi Focusky akan menghasilkan media pembelajaran yang dapat merangsang gaya belajar siswa dengan keunggulan metode drag and drop. Tujuan dari penelitian ini adalah untuk menghasilkan media pembelajaran menggunakan aplikasi Focusky yang dilengkapi dengan buku panduan tentang bahan protista untuk siswa kelas $\mathrm{X}$ yang valid. Penelitian ini adalah penelitian pengembangan (Research and Development) dengan model Instructional Development Institute (IDI) yang terdiri dari tahapan mendefinisikan, mengembangkan, dan mengevaluasi. Subjek penelitian adalah dua dosen biologi di FMIPA UNP dan satu guru biologi di SMAN 2 BatangAnai. Objek penelitian adalah media pembelajaran dengan menggunakan aplikasi Focusky pada protista materi yang dilengkapi dengan buku panduan untuk siswa sekolah menengah kelas X. Data penelitian adalah data primer dalam bentuk validitas data yang diperoleh langsung melalui pemberian kuesioner validasi kepada subjek penelitian. Berdasarkan hasil penelitian dihasilkan media pembelajaran menggunakan aplikasi Focusky pada materi protist yang dilengkapi dengan buku pedoman untuk siswa kelas X yang valid dengan nilai validitas rata-rata $88,82 \%$.
\end{abstract}

Kata Kunci: Validitas, Fokusky, Buku Panduan.

*Penulis Korespondensi:

Alamat surel: agathapratiwimail@gmail.com 


\section{PENDAHULUAN}

Pembelajaran adalah proses interaksi peserta didik dengan pendidik dan sumber belajar pada suatu lingkungan belajar. Pembelajaran merupakan perpaduan dari konsep belajar dan mengajar (Suardi, 2018: 7). Belajar adalah proses yang berlangsung dalam diri peserta didik untuk mengubah tingkah lakunya, sedangkan mengajar adalah usaha untuk menciptakan sistem lingkungan belajar yang nyaman untuk memungkinkan terciptanya proses belajar secara optimal. Sistem lingkungan belajar yang dimaksud terdiri dari tujuan pengajaran, guru, peserta didik, materi pelajaran, metode pengajaran, media pengajaran, dan faktor administrasi dan finansial (Neolakadan Grace, 2017: 18). Lingkungan belajar dalam hal terutama di kelas adalah sesuatu yang diupayakan atau diciptakan oleh guru agar proses pembelajaran kondusif dan dapat mencapai tujuan pembelajaran.

Penggunaan media dalam pembelajaran membantu guru dan peserta didik untuk memperjelas materi ajar agar tidak terlalu verbalistis, mengatasi keterbatasan ruang, waktu, tenaga, dan daya indera, menimbulkan gairah belajar, interaksi lebih langsung antara peserta didik dan sumber belajar, memungkinkan peserta didik belajar sesuai dengan gaya belajarnya, dan memberi rangsangan yang sama, mempersamakan pengalaman dan menimbulkan persepsi yang sama (Sumiharsono dan Hisbiyatul, 2017: 10-11). Tentunya penggunaan media pembelajaran harus sesuai dengan tuntutan dan kebutuhan pasar dan dapa tmengikuti perkembangan zaman. Lembaga pendidikan seharusnya merancang media pembelajaran dengan mengkaji dan memahami perkembangan teknologi informasi dan komunikasi dewasa ini (Yaumi, 2018: 14), agar terpenuhinya kebutuhan peserta didik sesuai tuntutan perkembangan zaman. Permasalahan ketersediaan media pembelajaran yang menarik memang masih perlu pemecahan. Di berbagai sekolah dikeluhkan kekurangan media pembelajaran, seperti halnya temuan Evriyanti dan Irawan (2019:5) yang mengungkapkan keadaan media pembelajaran di daerah kepulauan.

Media dalam pembelajaran berperan dalam meningkatkan motivasi belajar peserta didik karena pembelajaran akan lebih menarik perhatian mereka dan makna dari materi ajar akan menjadi lebih jelas sehingga dapat dipahami peserta didik dan memungkinkan terjadinya penguasaan serta pencapaian tujuan pembelajaran (Jalinus dan Ambiyar, 2016: 7). Berdasarkan hasil wawancara peneliti dengan salah satu guru biologi di SMAN 2 Batang Anai yaitu Ibu Wellismaida, S.Pd. pada tanggal 12 Maret 2019 bahwa peserta didik kurang termotivasi untuk belajar dengan menggunakan media pembelajaran yang tersedia yaitu papan tulis, slide power point, lembar kerja, buku cetak, alat-alatlaboratorium, dan video yang berkaitan. Hal tersebut juga dialami peneliti saat melaksanakan Program Pengalaman Lapangan Kependidikan (PPLK), bahwa peserta didik kurang termotivasi untuk memusatkan perhatian dalam memahami materi selama pembelajaran berlangsung. Pada awal pelajaran peserta didik cenderung tidak tertarik dengan materi pelajaran yang bukan disenanginya sehingga membuat peserta didik tidak fokus memperhatikannya (Sumiharsono dan Hisbiyatul, 2017: 12).

Keberhasilan pembelajaran secara keseluruhan sangat tergantung pada keberhasilan 
guru merancang materi pembelajaran. Berdasarkan hasil wawancara, salah satu materi pembelajaran biologi yang sulit dipahami pada materi kelas $\mathrm{X}$ adalah protista.Protista merupakan salah satu materi yang sulit dipahami karena rendahnya minat peserta didik dengan klasifikasi yang banyak dan dilatarbelakangi oleh tidak duduknya konsep atau pemahaman dasar biologi peserta didik. Peserta didik tidak bisa memaknai materi tersebut sehingga menjadikannya hafalan. Hal tersebut juga dibuktikan pada hasil observasi yang menyatakan $66,7 \%$ peserta didik memilih materi protista sebagai materi yang sulit dipahami. Pernyataan tersebut didukung oleh sebagian besar alasan peserta didik yang kesulitan dalam mengelompokkan protista dan memaknai gambar objek berdasarkan ciri-cirinya, penggunaan nama ilmiah pada contoh protista, dan objek yang bersifa tmikroskopis. Disadari atau tidak penggunaan media pembelajaran berpengaruh terhadap peningkatan pemahaman peserta didik dalam pembelajaran terhadap materi ajar (Jalinus dan Ambiyar, 2016: 7).

Salah satu peluang untuk mengembangkan media pembelajaran baik secara online maupun offline adalah kebutuhan yang disesuaikan dengan kemajuan teknologi. Media pembelajaran sebagai pendukung dalam menyampaikan materi haruslah inovatif dan menarik. Focusky menjadi salah satu aplikasi yang menjadi rekomendasi peneliti untuk mengembangkan media pembelajaran dengan mudah dan hasilnya sangat menarik. Aplikasi Focusky berfungsi sebagai media pembelajaran dengan kelebihan perbesaran dan pergeseran. Selain itu, Focusky lebih powerful dan menarik serta bisa digunakan secara online maupun offline (Idaharyani, 2017: 13).

Penelitian Huda dan Sulinda (2018) menyatakan bahwa Focusky dapat membantu dalam memahami penjelasan dalam pembelajaran. Selain itu Focusky juga membantu dalam memahami penjelasan dari sebuah proses sesuai hasil penelitian Cheng, dkk (2018) dan meningkatkan kemampuan berpikir kritis peserta didik karena menimbulkan gairah, perhatian, rasa ingin tahu, dan motivasi belajar pada hasil penelitian Najmul, dkk (2017). Berdasarkan hasil angket observasi dan wawancara didapatkan informasi bahwa SMAN 2 Batang Anai belum pernah menggunakan media pembelajaran menggunakan aplikasi Focusky. Ditinjau dari segi sarana dan prasarana yang ada di SMAN 2 Batang Anai, media pembelajaran menggunakan aplikasi Focusky memungkinkan untuk digunakan dalam proses pembelajaran.

Pengembangan media pembelajaran menggunakan aplikasi Focusky tentunya membutuhkan suatu panduan berupa buku untuk membantu pengguna dalam mengembangkan media. Buku panduan bertujuan untuk memandu atau menuntun pengguna dalam mengaplikasikannya. Hal tersebut didukung oleh penelitian Setiawati dan Handayani (2018) bahwa panduan memberikan respon positif terhadap penggunaannya yang mudah dan bermanfaat. Berdasarkan observasi literatur di Perpustakaan Jurusan Biologi FMIPA UNP, belum ada peneliti yang mengembangkan media pembelajaran yang dilengkapi buku panduan pembuatannya sehingga hal tersebu tmenjadi inovasi bagi peneliti dan berdasarkan observasi literatur dalam cakupan luas 
secara umum, Idaharyani (2017) telah menerbitkan buku panduan yang relevan dengan judul "Cara Mudah Membuat Media Pembelajaran Interaktif dengan Focusky". Kelemahan pada buku tersebut terletak pada isi buku yang hitam putih termasuk penyajian gambar-gambar hasil screenshot yang tidak berwarna, panduan yang digunakan masih menggunakan aplikasi Focusky versi 2.8.1, panduan yang diberikan berupa cara-cara penggunaan tools yang tersedia, dan belum menyajikan cara pembuatan media pembelajaran secara utuh dan spesifik dalam satu produk.

Berdasarkan permasalahan yang telah dikemukakan, maka peneliti hendak melakukan penelitian "Pengembangan Media Pembelajaran Menggunakan Aplikasi Focusky dilengkapi Buku Panduan pada Materi Protista untuk Peserta Didik Kelas X di SMAN 2 Batang Anai” sebagai solusi untuk menunjang pembelajaran.

\section{METODE PENELITIAN}

Penelitian ini adalah penelitian pengembangan (Research and Development) dengan model Instructional Development Institute (IDI). Penelitian ini bertujuan untuk menghasilkan sebuah produk yang dapat membantu mempermudah dan mengatasi permasalahan yang dihadapi (Prasetyo, 2015: 42). Penelitian dilakukan di Jurusan Biologi Fakultas Matematika dan Ilmu Pengetahuan Alam (FMIPA) Universitas Negeri Padang dan di SMAN 2 Batang Anai. Penelitian mulai dilaksanakan pada bulan April-Juni tahun2019.

Subjek penelitian adalah dua orang dosen biologi FMIPA UNP dan satu orang guru biologi SMAN 2 Batang Anai. Objek penelitian adalah media pembelajaran menggunakan aplikasi Focusky dilengkapi buku panduan pada materi protista untuk peserta didik kelas X. Data penelitian adalah data validitas yang diperoleh secara langsung melalui pemberian instrumen kepada subjek penelitian. Data validitas didapatkan dengan menganalisis angket uji validitas yang telah diisi oleh validator. Analisis dilakukan dengan beberapa langkah berikut ini.

a. Memberikan skor jawaban pada angket uji validitas dengan kriteria berdasarkan skala Likert sebagai berikut.

SS = Sangat Setuju dengan skor 4

$\mathrm{S} \quad=$ Setuju dengan skor 3

$\mathrm{TS}=$ Tidak setuju dengan skor 2

STS $=$ Sangat Tidak Setuju dengan skor 1

b. Menentukan skor tertinggi.

Skor tertinggi $=$ jumlah validator $\mathrm{x}$ jumlah indikator x skor jawaban maksimum.

c. Menentukan jumlah skor jawaban dari masingmasing validator dengan menjumlahkan semua skor jawaban yang diperoleh dari masingmasing indikator.

d. Menentukan nilai validitas dengan cara berikut ini.

Nilaivaliditas $=\frac{\text { jumlah skor yang diperoleh }}{\text { jumlah skor tertinggi }} \times 100 \%$

e. Mengategorikan nilai validitas yang telah dimodifikasi dari Purwanto (2012: 82) sebagai berikut.

$$
\begin{array}{ll}
90 \%-100 \% & =\text { sangat valid } \\
80 \%-89 \% & =\text { valid } \\
65 \%-79 \% & =\text { cukup valid } \\
55 \%-64 \% & =\text { kurang valid } \\
\leq 54 \% & =\text { tidak dapat digunakan }
\end{array}
$$

\section{HASIL DAN PEMBAHASAN}


Berdasarkan penelitian yang telah dilaksanakan di Jurusan Biologi FMIPA UNP dan di SMAN 2 Batang Anaipada bulan AprilJunitahun 2019 dengan subjek penelitian tiga orang validator, diperoleh hasil penelititan uji validitas. Uji validitas dilakukan untuk memeriksa kelayakan media pembelajaran menggunakan aplikasi Focusky pada materi protista untuk peserta didik kelas $\mathrm{X}$ dan buku panduan pembuatannya sesuai dengan aspek penilaian kelayakan isi, kebahasaan, penyajian, dan kegrafikan. Hasil penelitian validitas media pembelajaran menggunakan aplikasi Focusky pada materi protista untuk peserta didik kelasXdapat dilihat pada Tabel 1.

Tabel 1. Validitas Media Pembelajaran Menggunakan Aplikasi Focusky Dilengkapi Buku Panduan

\begin{tabular}{|c|c|c|c|c|c|c|c|}
\hline \multirow{2}{*}{$\begin{array}{c}\text { Aspek } \\
\text { Penilaia } \\
\text { n }\end{array}$} & \multicolumn{3}{|c|}{$\begin{array}{l}\text { Penilaian } \\
\text { Validator }\end{array}$} & \multirow{2}{*}{$\begin{array}{c}\mathrm{Ju} \\
\mathrm{mla} \\
\mathrm{h} \\
\text { Sko } \\
\mathrm{r}\end{array}$} & \multirow{2}{*}{$\begin{array}{l}\text { Skor } \\
\text { Terti } \\
\text { nggi }\end{array}$} & \multirow{2}{*}{$\begin{array}{l}\text { Nilai } \\
\text { Vali } \\
\text { ditas }\end{array}$} & \multirow{2}{*}{$\begin{array}{c}\text { Kateg } \\
\text { ori }\end{array}$} \\
\hline & $\mathrm{I}$ & II & $\begin{array}{c}\text { II } \\
\text { I }\end{array}$ & & & & \\
\hline $\begin{array}{l}\text { Kelaya } \\
\text { kan isi }\end{array}$ & $\begin{array}{l}1 \\
6\end{array}$ & $\begin{array}{l}1 \\
2\end{array}$ & $\begin{array}{l}1 \\
6\end{array}$ & 44 & 48 & $\begin{array}{l}91,6 \\
7 \%\end{array}$ & $\begin{array}{c}\text { Sanga } \\
\mathrm{t} \\
\text { valid }\end{array}$ \\
\hline $\begin{array}{l}\text { Kebaha } \\
\text { saan }\end{array}$ & $\begin{array}{l}2 \\
4\end{array}$ & $\begin{array}{l}2 \\
3\end{array}$ & $\begin{array}{l}2 \\
6\end{array}$ & 73 & 84 & $\begin{array}{c}86,9 \\
0 \%\end{array}$ & Valid \\
\hline $\begin{array}{l}\text { Penyaji } \\
\text { an }\end{array}$ & $\begin{array}{l}7 \\
4\end{array}$ & $\begin{array}{l}6 \\
8\end{array}$ & $\begin{array}{l}7 \\
6\end{array}$ & 218 & 252 & $\begin{array}{l}86,5 \\
1 \%\end{array}$ & Valid \\
\hline $\begin{array}{l}\text { Kegrafi } \\
\text { kan }\end{array}$ & $\begin{array}{l}6 \\
4\end{array}$ & $\begin{array}{l}5 \\
9\end{array}$ & $\begin{array}{l}6 \\
1\end{array}$ & 184 & 204 & $\begin{array}{l}90,2 \\
0 \%\end{array}$ & $\begin{array}{c}\text { Sanga } \\
\mathrm{t} \\
\text { valid }\end{array}$ \\
\hline & & & & & Total & $\begin{array}{l}355 . \\
28 \%\end{array}$ & \\
\hline & & & & & ta-rata & $\begin{array}{l}88.8 \\
2 \%\end{array}$ & Valid \\
\hline
\end{tabular}

Keterangan:
Validator I : Drs. Armen, S.U. (Dosen Biologi FMIPA UNP)

Validator II : Rahmadhani Fitri， M.Pd. (Dosen Biologi FMIPA UNP)

Validator III : Wellismaida, S.Pd. (Guru Biologi SMAN 2 Batang Anai)

Analisis data dari angket uji validitas media pembelajaran menggunakan aplikasi Focusky dilengkapi buku panduan pada materi protista untuk peserta didik kelas X SMA oleh validator yakni dosen dan guru didasarkan pada empat aspek penilaian yaitu, kelayakan isi, kebahasaan, penyajian, dan kegrafikan. Hasil analisis data menunjukkan bahwa media pembelajaran menggunakan aplikasi Focusky dilengkapi buku panduan pada materi protista untuk peserta didik kelas $X$ SMA yang dikembangkan dikategorikan valid dengan ratarata nilai validitas $88,82 \%$.

Ditinjau dari kelayakan isi, media pembelajaran menggunakan aplikasi Focusky dilengkapi buku panduan memiliki nilai validitas sebesar 91,67\% dengan kategori sangat valid. Hal ini menunjukkan bahwa media pembelajaran menggunakan aplikasi Focusky dilengkapi buku panduan yang dikembangkan telah sesuai dengan Kurikulum 2013 berdasarkan tuntutan Standar Kompetensi (SK), Kompetensi Dasar (KD), indikator pencapaian kompetensi, dan tujuan pembelajaran. Hal ini sejalan dengan yang dikemukakan Asyhar (2011: 159) bahwa "dalam pembuatan modul harus memperhatikan kesesuaian dengan kompetensi yang didasarkan pada kurikulum yang berlaku".

Ditinjau dari kebahasaan, media pembelajaran menggunakan aplikasi Focusky dilengkapi buku panduan pada materi protista 
untuk peserta didik kelas X SMA memiliki nilai validitas sebesar $86,90 \%$ dengan kategori valid. Hal ini menunjukkan bahwa media pembelajaran menggunakan aplikasi Focusky dilengkapi buku panduan yang dikembangkan telah memiliki susunan kalimat yang tepat, jelas dan sederhana sesuai dengan kaidah penulisan yang baik. Hal ini sesuai dengan Asyhar (2011: 157) yang menyatakan bahwa "dalam penulisan modul harus dirancang strategi untuk menarik perhatian sehingga siswa dapat memahami informasi (materi) yang disajikan". Jadi, salah satu strategi untuk menarik perhatian siswa agar termotivasi belajar menggunakan modul adalah dengan menyajikan materi ajar menggunakan bahasa yang sederhana, jelas, dan mudah dipahami.

Ditinjau dari penyajian, media pembelajaran menggunakan aplikasi Focusky dilengkapi buku panduan padamateriprotistauntukpesertadidikkelas X SMA memiliki nilai validitas $86.51 \%$ dengan kategori valid. Hal ini menunjukkan bahwa media pembelajaran menggunakan aplikasi Focusky dilengkapi buku panduan telah sesuai dengan indikator dan tujuan pembelajaran. Selain itu, kelengkapan materi ajar telah sesuai dengan urutan indikator sehingga peserta didik dapat belajar secara sistematis dan terarah.

Ditinjau dari kegrafikan, media pembelajaran menggunakan aplikasi Focusky dilengkapi buku panduanpadamateriprotistauntukpesertadidikkelas X SMA memiliki nilai validitas sebesar $90,20 \%$ dengan kategori sangat valid. Hal ini menunjukkan bahwa desain media pembelajaran menggunakan aplikasi Focusky dilengkapi buku panduan yang dikembangkan sudah baik dan menarik meliputi bentuk dan ukuran huruf yang sesuai, gambar, video, dan animasi yang disajikan menarik dan relevan dengan materi, serta pemilihan warna yang sesuai dan menarik. media pembelajaran menggunakan aplikasi Focusky dilengkapi buku panduan yang menarik akan mudah menarik perhatian peserta didik untuk menggunakannya.

\section{KESIMPULAN DAN SARAN}

\section{Kesimpulan}

Berdasarkan hasil penelitian dan
pembahasan yang telah dipaparkan dapat
disimpulkan bahwa media pembelajaran
menggunakan aplikasi Focusky dilengkapi buku
panduan pada materi protista untuk peserta didik
kelas X SMA valid dengan rata-rata nilai validitas
$88,82 \%$.

\section{Saran}

Berdasarkan penelitian yang telah dilakukan, dapat disarankan hal-hal sebagai berikut.

1. Guru dapat mengggunakan media pembelajaran menggunakan aplikasi Focusky dilengkapi buku panduan pada materi protista untuk peserta didik kelas X SMAdalam proses pembelajaran sebagai salah satu alternatif media pembelajaran yang bervariasi.

2. Penelitian selanjutnya dapat dilakukan pada materi lain karena penelitian ini terbatas pada materi protista dan dapat dilanjutkan dengan uji praktikalitas dan efektivitas.

\section{DAFTAR PUSTAKA}

Arsyad, A. 2009. Media Pembelajaran. Jakarta:PT. Raja Grafindo Persada.

Evriyanti, T., Irawan Bony, Muhartati, E. 2019. Profil Media Pembelajaran di SMP Negeri Se-Kecamatan Tanjungpinang Timur. Pedagogi Hayati Volume 3 No 1. 
https://doi.org/10.31629/pedag.\%20haya ti.v3i1.1125

Prasetyo, Eko. 2015. Ternyata Penelitian itu Mudah (Panduan Melaksanakan Penelitian Bidang Pendidikan).Jember: Edu Nomi.

Purwanto, M. Ngalim. 2012. Prinsip-Prinsip dan Teknik Evaluasi Pengajaran. Bandung: Remaja Rosdakarya.

Sukiman. 2012. Pengembangan Media Pembelajaran. Yogyakarta: Pedagogia. Purwanto, M. Ngalim. 2012. Prinsip-prinsip dan Teknik Evaluasi Pengajaran. Bandung: Remaja Rosdakarya.

W. S. Anwar, W. Liliawati, J. A. Utama . 2013. Penerapan Pembelajaran Konseptual Interaktif dengan Menggunakan Media Animasi Untuk Meningkatkan Penguasaan Konsep IPBA dan Mengetahui Profil Aktivitas Siswa SMP. WAPFI Journal. Vol. 1. No. 1. DOI:10.17509/wapfi.v1i1.4892 